\title{
Prostaglandins in inflammatory bowel disease therapy
}

\author{
LONNIE R EMPEY, BSC, RICHARD N FEDORAK, MD, FRCPC, FACP
}

LR EMPEY, RN FEDORAK. Prostaglandins in inflammatory bowel disease therapy. Can J Gastroenterol 1993;7(2):173-178. Because the etiology of inflammatory bowel disease (IBD) is unknown, attempts to find new therapies for this disease have focused on the soluble mediators that maintain and amplify the inflammatory response. The two major classes of mediators derived from membrane phospholipids are the metabolites arachidonic acid (eicosanoids) and platelet activating factor. These metabolites are major mediators in the processes of inflammation and the stimulation of intestinal secretion of water and electrolytes found in IBD. It is clear that the interaction between prostaglandins and leukotrienes is complex being both additive and antagonistic and, in this regard, it is impossible to separate the summation of their effects. Nevertheless, over the past several years, it has become clear that inhibition of leukotrienes using leukotriene biosynthesis inhibitors, leukotriene receptor antagonists or eicosapentanoic acid is beneficial in preventing and/or healing both experimentally-induced and human forms of IBD. In contrast, inhibition of prostaglandins does not improve experimentally-induced colitis and, in humans, may actually exacerbate the disease. By implication, leukotrienes may be injurious while prostaglandins are protective to intestinal mucosa. The mucosal protective effect of the prostaglandin analogue, misoprostol, during experimentally-induced colitis is not the consequence of alterations in bloodflow but rather the consequence of accelerated rate of restitution and repair. It remains to be determined whether the beneficial effects of prostaglandins in experimentally-induced models of colitis would also occur in human IBD. (Pour résumé, voir page 174)

Key Words: Eicosanoids, Inflammatory bowel disease, Leukotrienes, Misoprostol, Prostaglandins

Department of Medicine, Division of Gastroenterology, University of Alberta, Edmonton, Wherta

Correspondence and reprints: Dr Richard N Fedorak, Department of Medicine, Division of Gastroenterology, 519 Robert Newton Research Building, Edmonton, Alberta T6G 2C2.

Telephone (403) 492-6941, Fax (403) 492-7964 $\prod$ HE DIARRHEA OF INFLAMMATORY bowel disease (IBD) is the end result of a complex series of pathophysiological events which includes: the stimulation of water and electrolyte secretion as well as inhibition of ab. sorption; the stimulation of enteric nerves which enhances propulsive contractions and stimulates ion secretion; mucosal destruction accompanied by weeping and loss of plasma-like fluid and proteins; and nutrient maldigestion and malabsorption along with increased luminal osmolar load. Previous studies have implicated a number of the products of activated cells in the pathogenesis of both inflammation-induced diarrhea and chronic relapsing intestinal inflammation seen during IBD. These products include eicosanoids, prostaglandins ( $\mathrm{PGE}_{1}, \mathrm{PGE}_{2}$ ), leukotrienes and thromboxanes (TXA 2 ) oxygen radicals, immunoglobulins, cytokines (monokines and lymphokines) and proteases $(1,2)$.

Because the etiology of IBD is unknown, attempts to find new therapies for this disease have focused on the soluble mediators that maintain and amplify the inflammatory response. 


\section{Prostaglandines dans le traitement de la maladie intestinale inflammatoire}

RÉSUMÉ: Parce que l'étiologie de la maladie intestinale inflammatoire est inconnue, les tentatives pour trouver de nouvelles thérapeutiques se sont concentrées sur les médiateurs solubles qui maintiennent et amplifient la réponse inflammatoire. Les deux principales classes de médiateurs dérivés des phospholipides de la membrane sont les métabolites de l'acide arachidonique (éicosanoïde) et le facteur d'activation plaquettaire. Ces métabolites sont des médiateurs importants dans le processus de l'inflammation et de la stimulation de la sécrétion intestinale d'eau et d'électrolytes observée dans la maladie intestinale inflammatoire. Il est évident que l'interaction entre prostaglandines et leucotriènes est complexe puisque additive et antagoniste et à cet égard, il est impossible de distinguer la somme de leurs effets. Néanmoins, au cours des quelques dernières années, il est devenu clair que l'inhibition des leucotriènes à l'aide des inhibiteurs de la biosynthèse des leucotriènes, des antagonistes des récepteurs des leucotriènes ou de l'acide cicosapintanoïque a contribué à prévenir ou à guérir les formes de maladies intestinales inflammatoires chez l'humain ou induites en laboratoire. Par contre, l'inhibition des prostaglandines n'améliore pas la colite induite expérimentalement et, chez l'humain, peut en fait exacerber la maladie. Les leucotriènes peuvent être nuisibles alors que les prostaglandines protègent la muqueuse intestinale. L'effet protecteur du misoprostol, un analogue des prostaglandines, durant une colite induite expérimentalement n'est pas la conséquence d'altérations du débit sanguin, mais plutôt d'un taux accéléré de restitution et de réparation. Il reste à déterminer si les effets bénéfiques des prostaglandines dans les modèles expérimentaux de colite se produiraient également chez l'humain atteint de maladie intestinale inflammatoire.

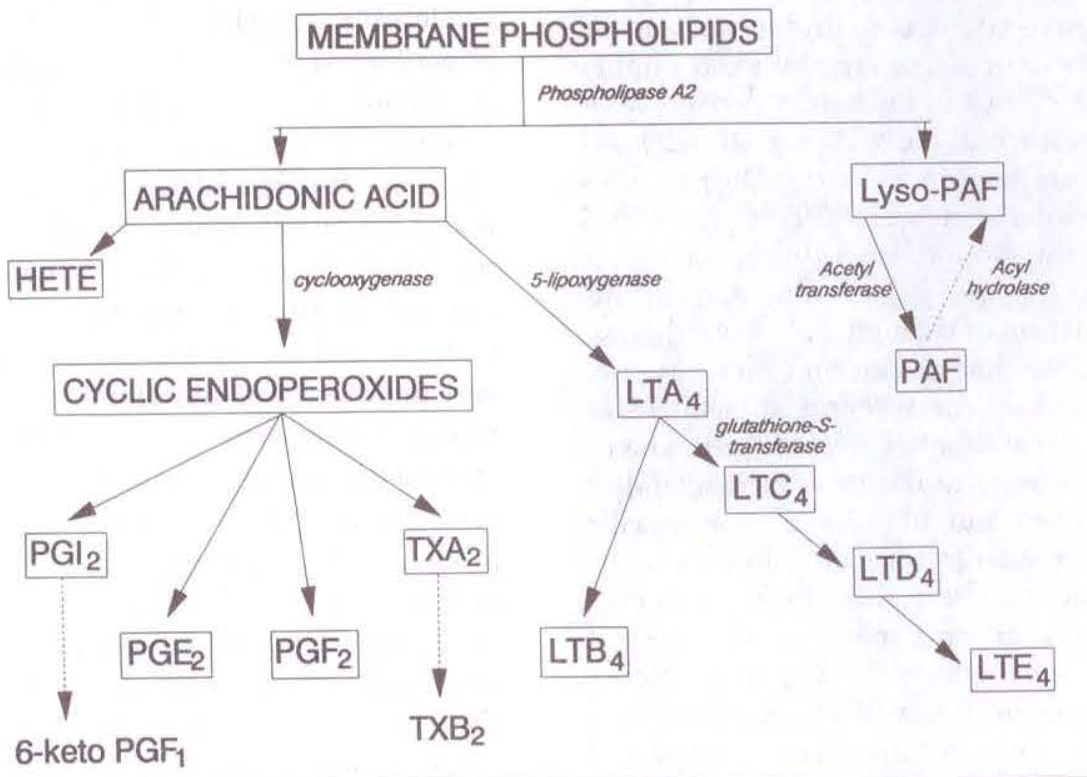

Figure 1) Pathways of eicosanoid and platelet activating factor formation for membrane phospholipids

Recently, potent inflammatory mediators derived from membrane phospholipids have been described and their role in the acute inflammation of IBD have been characterized (3). The two major classes of mediators derived from membrane phospholipids are the metabolites arachidonic acid (eicosanoids) and platelet activating factor (Figure 1). It is generally believed that these metabolites are major mediator in the processes of inflammation and the stimulation of intestinal secretion of water and electrolytes found in IBD While nearly all cells are capable of synthesizing arachidonic acid metabo lites, their synthetic capacities and the profiles of metabolites synthesized var significantly between cells. Arachidonic acid, like other fatty acids, is no found free in the cytosol but is esterifie into the membrane phospholipids. The activation of the enzyme phospholipas $A_{2}$ by mechanical, chemical or im munological stimuli releases arachi donic acid from membrane phospholip ids, making it available for metabolism by cyclooxygenase and lipoxygenas enzymes into prostaglandins and leuko trienes.

This review focuses on the role 0 prostaglandins in IBD and their potential use as novel therapeutic agents. Iti clear that the interaction between prostaglandins and leukotrienes is com plex, being both additive and antagonistic. In this regard, it is therefor impossible to separate the summation of their effects. Nevertheless, over the past several years, it has become cleat that inhibition of leukotrienes usin leukotriene biosynthesis inhibitors (4 7), leukotriene receptor antagonists (8 11), or eicosapentanoic acid (12-15) beneficial in preventing and/or healin, both experimentally-induced an human forms of IBD. In contrast, in hibition of prostaglandins does not im prove experimentally-induced colit and, in humans, may actually exacer bate the disease $(16-18)$. By implica tion, leukotrienes may be injuriou while prostaglandins are protective intestinal mucosa.

\section{CYCLOOXYGENASE PRODUCTS OF} ARACHIDONIC ACID

Individual prostaglandins known to have varying, and often op posite, effects in different tissues reiterating the complexity of pros. tanoids in gastrointestinal function Outlined below is a summary of the effects prostaglandins have, relevant to IBD, on small intestine and colonic function. 
Vascular effects: $\mathrm{PGE}_{2}, \mathrm{PGE}_{1}$, and $\mathrm{PGI}_{2}$ have all demonstrated potent vasodilator actions in canine and human mesenteric and mucosal bloodflow. The increased formation of these vasodilator prostaglandins in disease tissue may possibly increase bloodflow to the site of inflammation and thereby enhance plasma leakage from postcapillary venules. Alternatively, vasodilation may serve to remove toxic metabolites (nitric oxide, leukotrienes, oxygen free radicals) generated by surrounding inflammation. The vasoconstrictor and platelet aggregating properties of $\mathrm{TXA}_{2}$ and $\mathrm{PGF}_{2} \alpha$, may be of importance in aggravating bowel inflammation, since these properties can cause microvascular vasoconstriction and diminished intestinal blood flow. Furthermore, the importance of TXA2 in promoting acute intestinal inflammation is supported by the fact that thromboxane synthetase inhibitors suppress endotoxin-induced intestinal damage in the rat (19) as well as suppressing the development of chronic inflammation in the animal model of IBD (20). Thromboxane synthetase inhibitors or thromboxane receptor antagonists have yet to be evaluated in humans.

Motility effects: $P \mathrm{PE}_{1}, \mathrm{PGE}_{2}$, and $\mathrm{PGF}_{2 \alpha}$, stimulate longitudinal smooth muscle contractions in vitro and gastrointestinal motility in vivo in several species including guinea pig, dog, rat and human, following oral or intravenous administration. The actions of these prostaglandins and their analogues on small intestinal transit are complex and depend not only on the type of prostanoid but also on the dose and route of administration. In contrast to prostaglandins of the $E$ and $F$ series, PGL 2 and its stable analogue, $9 \beta$-methyl carbacyclin, have limited contractile action on isolated gastrointestinal tissue. $\mathrm{PGI}_{2}$ relaxes longitudinal muscle from segments of human intestine in vitro and antagonize the contractions induced by $\mathrm{PGE}_{2}$ and $\mathrm{PGF}_{2 \mathrm{a}}$. Prostaglandins, by affecting gastrointestinal motility, could thus contribute to both the diarrhea and abdominal pain seen in IBD patients.
Water and electrolyte transport effects: Inflamed tissue produces a number of potential secretagogues, and recent evidence suggests that prostaglandins could mediate the secretory responses to histamine, 5-hydroxytryptamine and kinins (21). Furthermore, these studies support the view that the synthesis of prostaglandins is largely confined to the subepithelial layer of the mucosa from which they pass to activate water and electrolyte transport in epithelial cells. Prostaglandins of the $E$ and $F$ series initiate diarrhea by inhibiting intestinal absorption of sodium and chloride, and stimulating chloride secretion through elevation of cyclic AMP levels (22). Although the stimulation of fluid secretion in the small intestine may contribute to the diarrhea of IBD, recent studies with 16,16-dimethyl $\mathrm{PGE}_{2}$ in rats following ligation of the ileocecal junction suggests that the watery stool originates in the cecum, and that acceleration of colonic transit is the primary mechanism of this diarrhea (23). The role of prostaglandins in the transport abnormalities of IBD thus remains unclear. The tachyphylaxis of the secretory response with repeated exposure of rabbit ileal mucosa in vitro to prostaglandins lends support to the evidence that increased prostaglandin production may not be a major determinant of the abnormalities of fluid and electrolyte transport seen during IBD (24).

Mucus effects: Prostaglandins applied in vitro to animal intestine increases the thickness of the microclimate of the mucosal surface by stimulating mucus secretion (25); however, limited information exists regarding the contribution of prostaglandins to the changes in volume and composition of mucus in IBD.

\section{PROSTAGLANDIN LEVELS IN HUMAN IBD}

Gould (26) was the first to report elevated concentrations of prostaglandins in stool from patients with an acute attack of ulcerative colitis. Since then, in vitro experiments with fresh biopsies of colonic mucosa obtained from patients with IBD have demon- strated increased concentrations of $\mathrm{PGE}_{2}, \mathrm{PGF}_{2} \alpha$ and 6-keto-PGF 1 (the stable, spontaneous breakdown product of $\left.\mathrm{PGE}_{2}\right)(27,28)$. Cultured, colonic mucosa taken from patients with active ulcerative colitis produces significantly higher amounts of $\mathrm{PGE}_{2}, 6-$ keto- $\mathrm{PGF}_{1 \mathrm{a}}$ and $\mathrm{TXB}_{2}$ than do normal controls, and these levels revert to normal during remission of the disease (29). The accumulation of $\mathrm{PGE}_{2}$ and $\mathrm{TXB}_{2}$ in the medium of cultured peripheral blood mononuclear cells and intestinal mononuclear cells from patients with Crohn's disease, but not ulcerative colitis, is significantly enhanced compared with that measured in the medium of cells from controls (29). Nevertheless, these measurements of tissue concentrations of prostaglandins may be suspect since these compounds are generally not stored and manipulation (eg, by biopsy) could activate membrane-bound phospholipases with subsequent artificial prostanoid formation. Similar limitations apply to tissue culture techniques. Finally, intestinal leukocytes behave differently from peripheral blood leukocytes in patients with IBD, emphasizing the limitation of data from studies of peripheral blood. Therefore, in vivo formation of prostanoids has been estimated by measuring the rate of $\mathrm{PGE}_{2}$ or equilibrium concentrations of $\mathrm{PGE}_{2}$ in dialysis bags placed in the empty rectum (30). These methods have demonstrated that luminal concentrations of prostaglandins and leukotrienes positively correlate with clinical, endoscopic and histological disease activity, decreasing towards normal levels in patients responding to therapy (30).

Despite these associations and the potential for prostaglandins' biological actions in IBD, this in itself does not establish causality. It remains to be determined whether the presence of prostaglandins is the cause or effect of the disease. Indeed, nonsteroidal anti-inflammatory drugs, potent inhibitors of cyclooxygenase and prostaglandin production, are of no benefit and may actually exacerbate IBD (16). Therefore, prostaglandins may, by implication, play a protective role in maintaining mucosal integrity. 


\section{CLINICAL IMPLICATIONS OF PROSTAGLANDINS IN HUMAN IBD}

Rapidly growing understanding of the inflammoregulatory and effector eicosanoids may permit new therapeutic approaches to IBD treatment. At present, the drugs used in IBD treatment nonspecifically decrease eicosanoid production and activity; in addition, these drugs have a multitude of effects on cytokines and oxygen radical scavenging. Novel therapeutic agents designed to specifically upand/or down-regulate individual eicosanoid synthesis and/or receptor binding may thus more effectively and efficiently prevent the amplification of inflammatory response while serving as effective agents in disease management. However, in the case of IBD, where there is both acute and chronic inflammation, the eicosanoids formed from membrane phospholipids engage in complex actions which may contribute to inflammation while also modulating the activity of lymphocytes and macrophages so as to suppress disease activity. Therefore, a balance of eicosanoid production may be of critical importance.

\section{EXOGENOUS \\ PROSTAGLANDIN \\ ANALOGUES}

It has been suggested that the in vivo elevation of endogenous prostaglandin levels seen in IBD may actually assist in protecting the mucosa from insult $(31,32)$. Exogenous prostaglandins in the stomach have certainly been shown to have mucosal protective effects, preventing the gastric necrosis produced by such agents as ethanol, hydrochloric acid, sodium hydroxide, hypertonic sodium chloride, taurocholate and thermal injury $(32,33)$. Only recently, however, have exogenous prostaglandins, been tested on experimental models of colonic inflammation. 16,16-dimethyl $\mathrm{PGE}_{2}$ intraluminally administered prior to induction of colitis significantly protects colonic mucosa from the injurious effects of $30 \%$ ethanol $(34,35)$. As well, Allgayer et al (36) have shown that intraluminal 16,16-dimethyl
$\mathrm{PGE}_{2}$ significantly protects colonic mucosa of rats from the damaging effects of trinitrobenzene sulphonic acid when administered before induction of colitis, and accelerates the healing and prevents the development of long term architectural changes when administered after induction of colitis. This effect of 16,16-dimethyl PGE 2 is not limited to its application as an intraluminal enema but is also effective when administered parenterally, inducing a dose-dependent suppression of inflammation in experimentally-induced rabbit colitis (37). Prostaglandins have demonstrated a similar mucosal protective effects in small intestine. PGI 2 and misoprostol have been shown to inhibit indomethacin-induced small intestinal lesions in a dose-dependent manner (38). Further evidence for the beneficial effect of prostaglandins comes from the fact that drugs which selectively inhibit endogenous prostaglandin production (eg, nonsteroidal antiinflammatory drugs) are of no therapeutic benefit to patients with IBD and, when associated with reduced levels of prostaglandins in the urine and rectum, may actually aggravate colonic mucosal inflammation (16-18,39). Although these studies measured morphologic injury, they did not assess the effect of prostaglandins on fluid and electrolyte transport, stimulation of which would serve only to enhance diarrhea during IBD.

Recently, the intraluminal application of a PGE 1 analogue (misoprostol) was shown to provide an epithelial and mucosal protective effect in the colonic mucosa of experimentally-induced colitis in rats $(40-42)$. Misoprostol therapy is dose and time dependent in its ability both to protect colonic tissue from macroscopic and microscopic ulceration and maintain normal in vivo colonic fluid absorption (40). Furthermore, misoprostol exhibits its mucosal protective effects whether administered before the induction of colitis or given after colitis has been induced (41). Subsequently, intraluminal preadministration of misoprostol has been shown to attenuate the increase in epithelial permeability and histamine release in rabbit distal small intestine injured with acetic acid and bovine casein (42). The mechanism(s) responsible for the beneficial mucosal protec. tive effects of prostaglandins remain largely undetermined. Since misopros. tol preserves crypt chloride secretion but not villus tip sodium absorption, misoprostol in experimentally-induced colitis models may preferentially protect the crypt base but not the villus tip epithelium (41). Indeed, in the small intestine 16,16-dimethyl $\mathrm{PGE}_{2}$ induces villus contraction reducing the surface area available for contact injury and, thus, may protect the crypt base through this mechanism (43). Recently, Yamada et al $(44,45)$ have demon. strated that the mucosal protective effect of intraluminilly administered misoprostol during acetic acid-induced colitis is not the consequence of pros. taglandin-induced alterations in bloodflow but rather the consequence of accelerated rate of colonocyte restitution and repair. Whether this colonic mucosal repair process is caused by the migration of uninjured enterocytes into injured areas or by the replacement of injured cells through preserved cell replication in the crypt base remains unknown. Prostaglandins may enhance one or both of these processes either directly or indirectly via the formation of growth promoting substances Similarly, administration of oral misoprostol ( $300 \mu \mathrm{g} / \mathrm{kg} /$ day) for 11 weeks to noncolitic dogs resulted in a significant increase in colonic crypt length and crypt cell population (46). In this study, misoprostol had no significant effect on either colonocyte migration rate or colonocyte transit rate (46).

The present experimentally-induced models of intestinal inflamma. tion do not approximate that of human IBD, although the trinitrobenzene sul phonic acid-induced colitis is immune mediated and does have a chronic phase. Thus, it remains to be deter mined whether the beneficial effects of prostaglandins described in experimen tally-induced models of colitis would also occur in human IBD. Indeed, ad ministration of exogenous $\mathrm{PGE}_{2}$ ana logues to patients with ulcerative colitis resulted in deterioration in eight of 12 treated patients (47), while life 
threatening diarrhea developed after short term misoprostol use in a single patient with Crohn's ileal colitis (48). The development of agents capable of up-regulating endogenous prostaglandins, without inducing adverse intestinal secretory side effects, is desired.

ACKNOWLEDGEMENTS: Dr Fedorak is a recipient of a Clinical Investigatorship from the Alberta Heritage Foundation of Medical Research. This work is supported in part by grants from the Medical Research Council of Canada and the Canadian Foundation for Ileitis and Colitis.

\section{REFERENCES}

1. MacDermott RP, Stenson WF.

Alterations of the immune system in ulcerative colitis and Crohn's disease. Adv Immunol 1988;42:285-328.

2. Elson CO. The immunology of inflammatory bowel disease. In: Kirsner JB, Shorter RG, eds. Inflammatory Bowel Disease. Philadelphia: Lea \& Febiger, 1988:97-164.

. Houghton-Smith N, Pettipher R. Lipid mediators and cytokines in inflammatory bowel disease. Eur J Gastroenterol Hepatol 1990;2:241-5.

4. Gillard J, Ford-Hutchinson AW, Chan C, et al. L-663,536 (MK-886)

(3-[I-\{4-chlorobenzyl\}-3-t-butyl-thio -5-isopropylindol-2-yl]-2,2-dimethylpropanoic acid), a novel, orally active leukotriene biosynthesis inhibitor. Can J Physiol Pharmacol 1989;67:456-64.

5. Wallace JL, Keenan CM. An orally active inhibitor of leukotriene synthesis accelerates healing in a rat model of colitis. Am J Physiol 1990;258:G527-34.

6. Collawn C, Rubin P, Perez N, et al. Experimental use of a 5-lipoxygenase inhibitor (Abbott-64077) in human ulcerative colitis (UC). Am J Gastroenterol 1989;184:1187A. 7. Laursen LS, Naesdal J, Bukhave K, Lauritsen K, Rask-Madsen J. Selective 5-lipoxygenase inhibition in ulcerative colitis. Lancet 1990;335:683-5.

8. Hawthome AB, Houghton-Smith N, Kurlak LO, Whittle BJR, Hawkey CJ. Lipoxygenase inhibitors in inflammatory bowel disease. Gut 1989;30:A1501.

. Fretland DJ, Levin S, Tsai BS, et al. The effect of leukotriene $\mathrm{B}_{4}$ receptor antagonist, SC-41930, on acetic acid-induced colonic inflamation. Agents Actions 1989;27:395-7. 0. Fretland DJ, Widomski D, Tsai BS,

\section{CONCLUSIONS}

It is apparent that the inflammoregulatory activities of eicosanoids (prostaglandins and leukotrienes) are involved in the pathogenesis of IBD. Emerging understanding of these products will allow for development of

et al. Effect of the leukotriene $\mathrm{B}_{4}$ receptor antagonist SC-41930 on colonic inflammation in rat, guinea pig and rabbit. J Pharmacol Exp Ther 1990;255:572-6.

11. Neilsen $\mathrm{OH}$, Ahnfelt-Rønne I, Thomsen MK, Kissmeyer A-M, Langholz E. Effect of the leukotriene $\mathrm{LTD}_{4} / \mathrm{LTE}_{4}$ antagonist, SR 2640, in ulcerative colitis: An open clinical study. Prostaglandins Leukotr Essent Fatty Acids 1991;42:181-4.

12. Empey LR, Jewell LD, Garg ML, Thomson ABR, Clandinin MT, Fedorak RN. Fish oil-enriched diet is mucosal protective against acetic acid-induced colitis in rats. Can J Physiol Pharmacol 1991;69:480-7.

13. McCall TB, O'Leary D, Bloomfield J, O'Morain CA. Therapeutic potential of fish oil in the treatment of ulcerative colitis. Aliment Pharmacol Ther 1989;3:415-24.

14. Solomon P, Asher AK, Janowitz HD. Treatment of ulcerative colitis with fish oil n-3-w-fatty acid: An open trial. J Clin Gastroenterol 1990;12:157-61.

15. Lorenz R, Weber PC, Szimnau P, Heldwein W, Stresser T, Loeschke K. Supplementation with $\mathrm{n}-3$ fatty acids from fish oil in chronic inflammatory bowel disease - a randomized, placebo-controlled, double-blind, cross-over trial. J Intern Med 1989;225(Suppl 1):225-32.

16. Kaufmann HJ, Taubin HL. Nonsteroidal anti-inflammatory drugs activate quiescent inflammatory bowel disease. Ann Intern Med 1987;107:513-6.

17. Wallace JL, Keenan CM, Gale D, Shoupe TS. Exacerbation of experimental colitis by nonsteroidal anti-inflammatory drugs is not related to elevated leukotriene $B_{4}$ synthesis. Gastroenterology 1992;102:18-27.

18. Empey LR, Walker K, Fedorak RN. Indomethacin worsens and a leukotriene biosynthesis inhibitor accelerates mucosal healing in rat colitis. Can J Physiol Pharmacol. (In press)

19. Boughton-Smith NK, Hutcheson I, Whittle BJR. Relationship between Pafacether and thromboxane $\mathrm{A}_{2}$ biosynthesis in endotoxin-induced intestinal damage in the rat. novel therapeutic agents which will be less pharmacologically toxic than current treatments. Furthermore, these novel therapeutic agents will also serve as tools by which to examine further the role played by eicosanoids in human IBD.

Prostaglandins 1989;38:319-33

20. Vilaseca J, Salas A, Guamer F, Rodriguez R, Malagelada JR.

Participation of thromboxane and other eicosanoids in the course of experimental inflammatory colitis. Gastroenterology 1990;98:269-77.

21. Rampton DS, Hawkey CJ.

Prostaglandins in ulcerative colitis. Gut 1984;25:1399-413.

22. Kimberg DV, Field M, Gershon E, Henderson A. Effects of prostaglandins and cholera enterotoxin on intestinal mucosal cyclic AMP accumulation. J Clin Invest 1974;53:941-9.

23. Rush BD, Ruwart MJ. The role of accelerated colonic transit in prostaglandin-induced diarrhea and its inhibition by prostacyclin. Br J Pharmacol 1984;83:157-9.

24. Rampton DS, Sladen GE. Relationship between rectal mucosal prostaglandin production and water and electrolyte transport in ulcerative colitis. Digestion 1984;30:13-22.

25. Satchithanandam S, Cassidy MM, Kharroubi AT, Calvert RJ, Leeds AR, Vahouny GV. Alterations in rat intestinal mucin patterns following luminal infusion of acetylsalicylic acid and prostaglandin derivatives. Dig Dis Sci 1990;35:1518-27.

26. Gould SR. Prostaglandins, ulcerative colitis and sulphasalazine. Lancet 1975;ii:988.

27. Hawkey CJ, Karmeli F, Rachmilewitz D. Imbalance of prostacyclin and thromboxane synthesis in Crohn's disease. Gut 1983;24:881-5.

28. Lauritsen K, Laursen LS, Bukhave K, Rask-Madsen J. In vivo profiles of eicosanoids in ulcerative colitis. Crohn's colitis and Clostridium difficile colitis. Gastroenterology 1989;95:11-7.

29. Rachmilewitz D. Prostaglandins in inflammatory bowel disease. In: Goebell H, ed. Inflammatory Bowel Diseases, Lancaster: MTP Press, 1988:137

30. Laufitsen K, Laursen LS, Bukhave K, Rask-Madsen J. Effects of topical 5-aminosalicylic acid and prednisolone on prostaglandin $\mathrm{E}_{2}$ and leukotriene $\mathrm{B}_{4}$ levels determined by equilibrium in vivo dialysis of rectum in relapsing ulcerative colitis. Gastroenterology 1986;91:837-44. 
31. Hillier K, Mason PJ, Pacheco S, Smith CL. Ulcerative colitis: Effect of sulphasalazine, its metabolites and indomethacin on the ability of human colonic mucosa to metabolize prostaglandin in vitro. $\mathrm{Br} \mathrm{J}$ Pharmacol 1982;76:157-61.

32. Robert A, Nezamis JE, Lancaster C, Hanchar AJ. Cytoprotection by prostaglandins in rats. Gastroenterology 1979;77:433-43.

33. Robert A, Nezamis JE, Lancaster C, Davies JP, Field SO, Hanchar AJ. Mild irritants prevent gastric necrosis through 'adaptive cytoprotection' mediated by prostaglandins. Am J Physiol 1983;245:G113-21.

34. Wallace JL, Whittle BJ, HoughtonSmith NK. Prostaglandin protection of rat colonic mucosa from damage induced by ethanol. Dig Dis Sci 1985;30:866-76.

35. Psaila JV, Myers B, Jones IR, Rhodes J. Effect of prostaglandin $\mathrm{PGE}_{2}$ on alcohol-induced ulceration in the rat colon. Digestion 1986;35:224-8.

36. Allgayer $\mathrm{H}$, Deschryver $\mathrm{K}$, Stenson WF. Treatment with 16,16'-dimethyl prostaglandin $\mathrm{E}_{2}$ before and after induction of colitis with trinitrobenzene sulfonic acid in rats decreases inflammation. Gastroenterology 1989;96:1290-300.

37. Schumert R, Nast CC, Cominelli F, Zipser RD. Effects of 16,16-dimethyl prostaglandin $\mathrm{E}_{2}$ and indomethacin on leukotriene $\mathrm{B}_{4}$ and inflammation in rabbit colitis. Prostaglandins 1988;36:565-77.

38. Bjarnason I, Smethurst P, Fenn CG, Lee CE, Menzies IS, Levi AJ. Misoprostol reduces indomethacininduced changes in human small intestinal permeability. Dig Dis Sci 1989;34:407-11.

39. Rampton DS, Barton TP. Are prostaglandins cytoprotective in the human large intestine? The effect of indomethacin on rectal mucosal function and prostaglandin $E_{2}$ release in vivo. Agents Actions 1984; 14:715-8.

40. Fedorak RN, Empey LR, MacArthur C, Jewell LD. Misoprostol provides a colonic mucosal protective effect during acetic acid-induced colitis in rats. Gastroenterology 1990;98:615-25.

41. Torsher KI, Empey LR, Fedorak RN. Misoprostol therapy following trinitrobenzene sulfonic acid-induced colitis accelerates healing.

Prostaglandins Leukotr Essent Fatty Acids 1992;45:275-81.

42. Miller MJS, Zhang X-J, Gu X, Clark DA. Acute intestinal injury induced by acetic acid and casein: Prevention by intraluminal misoprostol. Gastroenterology 1991;101:22-30.

43. Erickson RA, Tamawski A, Dines G, Stachura J. 16,16-dimethyl prostaglandin $\mathrm{E}_{2}$ induces villus contraction in rats without affecting intestinal restitution. Gastroenterology 1990;99:708-16.

44. Yamada T, Specian RD, Granger DN Gaginella TS, Gresham MB.

Misoprostol attenuates acetic acid-induced increases in mucosal permeability and inflammation: Role of bloodflow. Am J Physiol 1991;261:G332-9.

45. Yamada T, Fujimoto K, Tso P, Fujimoto T, Gaginella TS, Gresham MB. Misoprostol accelerates colonic mucosal repair in acetic acid-induced colitis. J Pharmacol Exp Ther 1992;260:313-8.

46. Goodlad RA, Mandir N, Levin S, Allen JL, Wright NA. Prostaglandins and the colonic epithelium. Effects of misoprostol on crypt size, cell production, and cell migration in the dog. Gastroenterology 1991;101:1229-34.

47. Goldin E, Rachmilewitz D. Prostanoid's cytoprotection for maintaining remission in ulcerative colitis. Failure of 15(R), 15-methyl. prostaglandin $\mathrm{E}_{2}$. Dig Dis Sci 1983;28:807-11.

48. Kombluth A, Gupta R, Gerson CD. Life-threatening diarrhea after short-term misoprostol use in a patien with Crohn ileocolitis. Ann Intern Med 1991;113:474-5. 


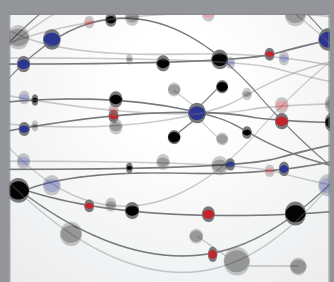

The Scientific World Journal
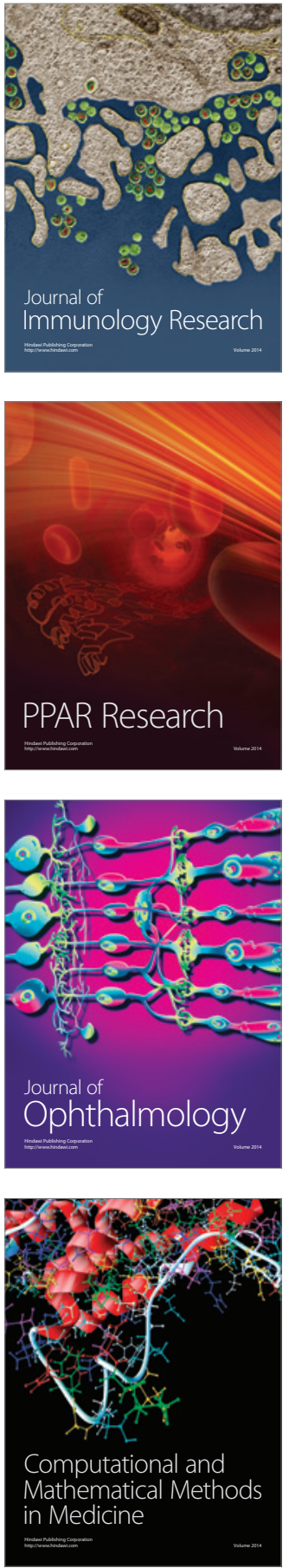

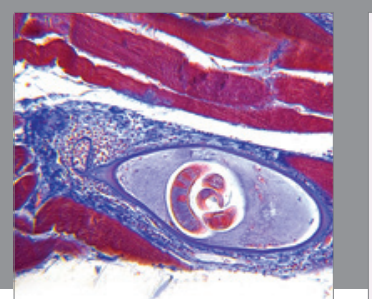

Gastroenterology Research and Practice

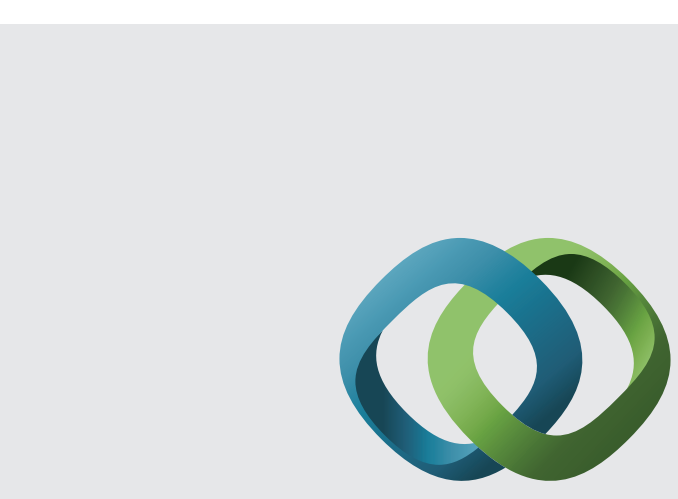

\section{Hindawi}

Submit your manuscripts at

http://www.hindawi.com
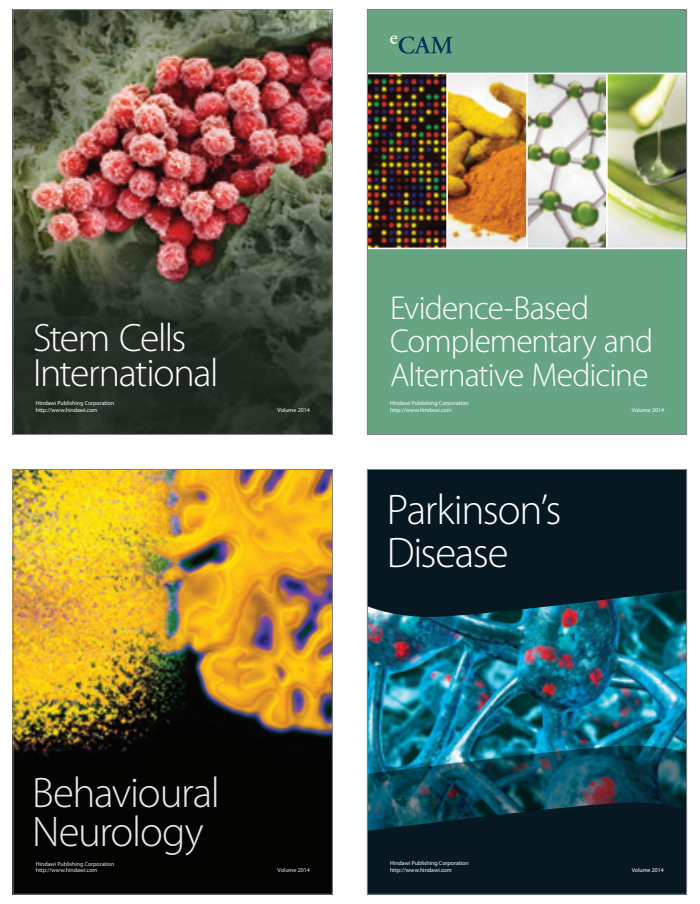
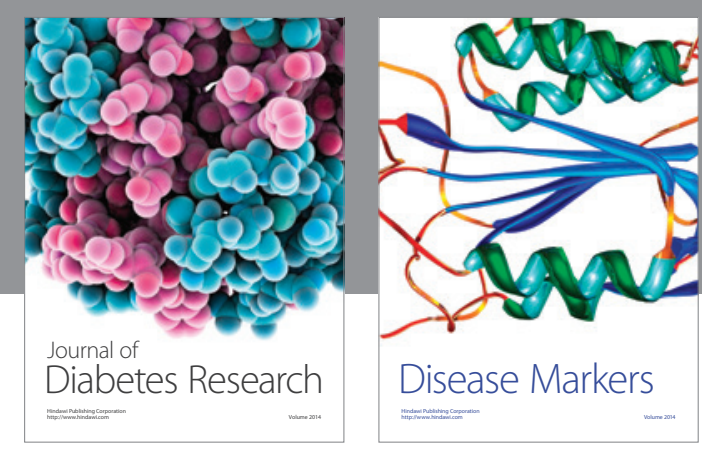

Disease Markers
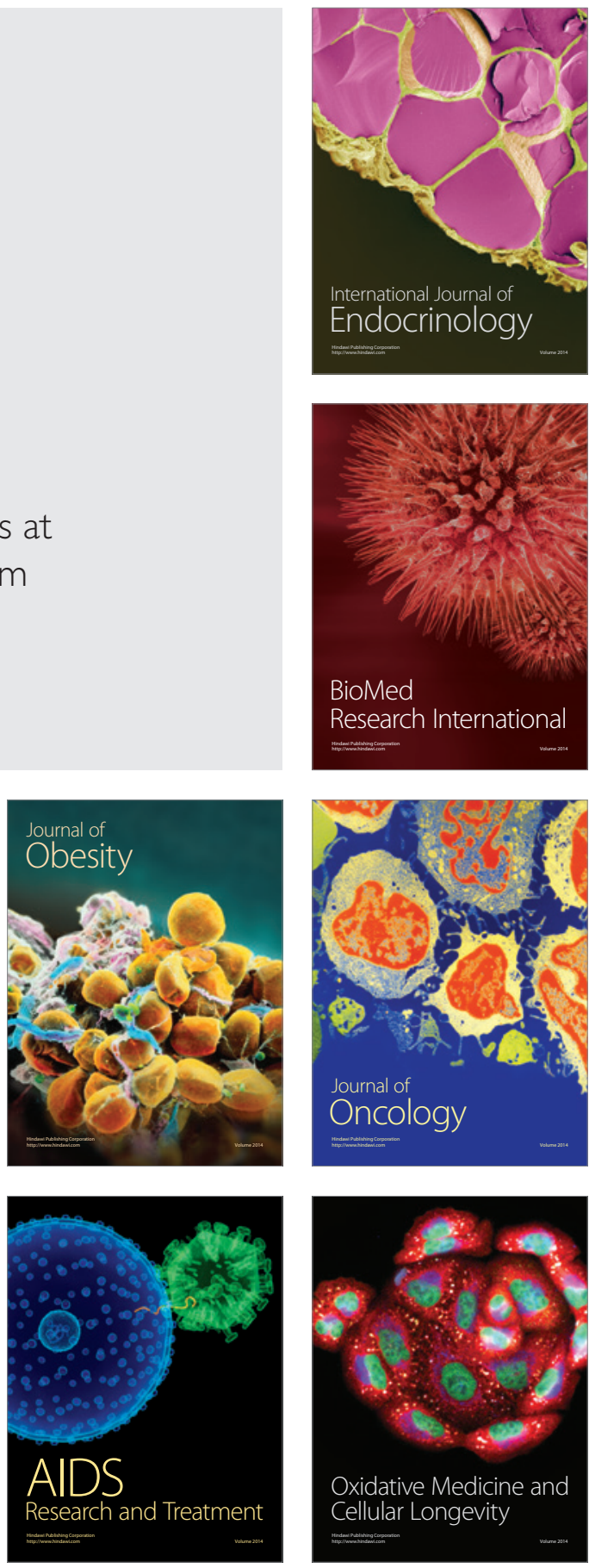